\title{
Links between Future Thinking and Autobiographical Memory Specificity in Major Depression
}

\author{
Ali Sarkohi ${ }^{1,2}$, Jonas Bjärehed $^{3}$, Gerhard Andersson ${ }^{1,4}$ \\ ${ }^{1}$ Department of Behavioural Sciences and Learning, Linköping University, Swedish Institute for Disabil- \\ ity Research, Linköping, Sweden; \\ ${ }^{2}$ Department of Psychiatry, Linköping University Hospital, Linköping, Sweden; \\ ${ }^{3}$ Department of Psychology, Lund University, Lund, Sweden; \\ ${ }^{4}$ Section of Psychiatry, Department of Clinical Neuroscience, Karolinska Institute, Stockholm, Sweden. \\ Email: Gerhard.Andersson@liu.se \\ Received January $3^{\text {rd }}, 2011$; revised February $28^{\text {th }}$, 2011; accepted April $9^{\text {th }}, 2011$.
}

\begin{abstract}
The aim of this study was to examine the association between autobiographical memory specificity and future thinking in a depressed sample. A total of 88 individuals who meet the DSM-IV criteria of major depression were included and completed the autobiographical memory test (AMT) and the future thinking task (FTT). The FTT was an index of number of future plausible events, rating of likelihood and emotional valence. The results showed that positive future thinking was significantly correlated with retrieval of specific positive autobiographical memories $(r=0.23)$. Moreover, correlational analyses showed that positive autobiographical memories were negatively correlated with extended autobiographical memories, repeated autobiographical memories, semantic associations and non-responses on the AMT. Self-report measures of depression and anxiety were not correlated with either the FTT or the AMT. The results of this cross-sectional study only give weak support for an association between autobiographical memory specificity and future thinking.
\end{abstract}

Keywords: Depression, Prospective Cognitions, Autobiographical Memory, Future Thinking

\section{Introduction}

Future thinking and autobiographical memory are known as important aspects of cognitive functioning (Schacter, Addis, \& Buckner, 2007), which both influence and can be influenced by depression. Future thinking can be defined as people's views of the future in terms of their cognitions about the future (MacLeod, Byrne, \& Valentine, 1996). Autobiographical memory is commonly described as a memory system consisting of episodes recollected from an individual's life. These memories can be based on a combination of personal experiences about specific objects, people and events experienced at particular time and place, and general knowledge and facts about the world (Conway \& Pleydell-Pearce, 2000). There are indications that the ability to imagine both positive and negative plausible future experiences is important for psychological well being, and might play an important role in the process of recovery, persistence and relapse of depression (MacLeod \& Moore, 2000). The ability to retrieve specific memories and perceiving positive future experiences are most likely important aspects for the maintenance of mental health. Pillemer (2003) suggested that memories have important directive functions, as they inform, guide, motivate and inspire behavior. Memories provide models for present and future activities and contribute to successful interpersonal communication, problem solving, organizing activity and performance (Williams, 2006). Reduced ability to generate specific autobiographical memories is a well replicated phenomena in clinical depression (Williams et al., 2007). Dalgleish et al. (2007) systematically examined eight studies and found that increased depressed mood was significantly related to reduced autobiographical memory specificity and that it was also associated with decreased executive control and poorer problem solving performance.

Clinical and experimental observations have also indicated that depression is associated with a decreased ability to generate anticipated future events (Macleod, Tata, Kentish, Carroll, $\&$ Hunter, 1997). One way to measure future-directed cognitions was initiated by MacLeod and coworkers, who developed a test based on the verbal fluency paradigm (MacLeod, Rose, \& Williams, 1993). In this test, referred to as the future thinking task (FTT), participants are asked to generate positive and negative things that they think are going to happen in the future. Several researchers have suggested that autobiographical memory specificity and ability to report future events are related in the sense that non-specific memories should be linked to a decreased ability to foresee future events. Williams et al. (1996) suggested that the factors that influence the phenomenology of past events influence future events in the same way. Retrieving past events and imaging future events both require the binding of details into a coherent event. There is however not much research on depressed samples to support a link between autobiographical memory specificity and the ability to report future events. Dalgleish et al. (2003) conducted a study on patients with eating disorders and found that autobiographical memory specificity was significantly correlated with the number of specific events generated on the FTT (Dalgleish et al., 2003). This was consistent with a finding by Williams et al. (1996) who studied a non-clinical sample and found a correlation between autobiographical memory specificity and specificity of future imagined events (Williams et al., 1996). Dickson and Bates (2006) reported that dysphoric individuals were less specific than controls when reporting both past and future events using 
positive and negative cue words (Dickson \& Bates, 2006). Kremers et al. (2004) compared outpatients with borderline personality disorder and controls on social problem solving capabilities and specificity of imagined future events. Patients with borderline personality disorder reported fewer active means to solve interpersonal problems and depressed patients with borderline personality disorder tended to have more difficulties in imagining positive future events in a specific way compared to controls. Specificity and problem solving were weakly related in patients with borderline personality disorder. Kremers et al. (2004) consequently suggested that social problem solving deficits in borderline personality disorder may be a consequence of disturbed emotion regulation rather than a consequence of restricted memory accessibility.

In spite a few studies on the association between autobiographical memory specificity and future thinking less is known regarding this association in persons with major depression. As both autobiographical memory specificity and future thinking have been found to be affected in persons with depression it is however likely that the two are associated. The aim of this study was to examine the relationship between future-oriented thinking and autobiographical memory in a sample of depressed subjects. We hypothesized that a positive association would be found between future events and specific autobiographical memories.

\section{Methods}

\section{Participants}

Participants in the study were assessed in association with a randomized controlled trial on two ways to deliver Internetbased treatment for major depression (Vernmark et al., 2010).

Detailed description of the protocol can be found in the original study. In this paper we report data from the pre-treatment structured interview which included the structured interview for the DSM-IV (First, Gibbon, Spitzer, \& Williams, 1997), the controlled word association test (Lezak, 1995), the autobiographical memory test, and the future thinking task. In total, 88 persons who meet the criteria of major depression using DSM-IV (American Psychiatric Association, 2000) completed the test protocol. There were $28(31.8 \%)$ males and 60 $(68.2 \%)$ females aged $19-69$ years $(M=36.8, S D=12.9)$. A minority of $17(19.3 \%)$ were on current stable medication.

\section{Procedure}

The study population was recruited through a variety of print (press release and articles in newspaper) and electronic media in Sweden. The information regarding the study was given, including the address of a website that provide general information and instructions on how to proceed for participation in the study. This included giving informed consent, which was done by e-mail. On this website participants were instructed to answer questions about gender, age, occupation, medication, previous therapy, expectations and complete a set of self-report inventories.

The following inclusion criteria were used: age 18 years or older; a total score on the Montgomery Åsberg depression rating scale (MADRS-S) between 15 - 30 (mild-to- moderate depression); a score of less than 4 on item 9 (zest for life) on the
MADRS-S (used to reduce any risk of including participants in need of more extensive treatment); giving informed consent (done by e-mail); no antidepressant medication initiated or changed in dosage during the last month (stable medication allowed); no ongoing psychotherapy; a diagnosis for major depression according to SCID-I; no psychotic states, bipolar disorder, alcohol and/or substance abuse problems.

Those who met the criteria for major depression according to self report inventories (pre-measure) were invited to a structured interview using the Structured clinical Interview for DSM IV ( SCID-I) (First et al., 1997). Thereafter participants completed the Controlled Word Association Test (COWAT); (Lezak, 1995), the AMT (Williams, 2001) and the FTT (MacLeod et al., 1993).

\section{Self-Assessments}

We used four self-report measures. The MADR-S consists of 9 items and used to measure depressive symptoms (Svanborg \& Åsberg, 2001). As a second measure of depressive symptoms we used the 21-item Beck Depression Inventory - BDI (Beck, Ward, Mendelson, Mock, \& Erbaugh, 1961). As a measure of anxiety we used the 21-item Beck Anxiety Inventory-BAI (Beck, Epstein, Brown, \& Steer, 1988). The BAI was specifically designed to discriminate anxiety from depression. Physiological and cognitive components of anxiety are addressed in 21 items. Finally, we used the Quality of Life Inventory-QoLI (Frisch, Cornell, Villanueva, \& Retzlaff, 1992). This measure includes 16 dimensions of life (e.g. health, economy). For each dimension a rating is made regarding importance (scored 0 to 2 ) and of how pleased the person is with that dimension (scored -3 to +3 , but with no 0 alternative). The QoLI has been reported to have satisfactory reliability and validity (Frisch et al., 1992). Psychometric properties for the MADRS-S, BDI and BAI are also robust.

The future thinking task (FTT) and the controlled word association test (COWAT)

The FTT is a verbal test in which participants are asked to think of potential future events/experiences across three time periods: next week, next year, and the next 5 - 10 years (MacLeod et al., 1993). This is completed for both positive and negative future events, with 1 minute given for each time period. The participant is required to come up with as many potential events as possible and to estimate the likelihood (between 1 - 7) for each event and a rating of emotional responses (between -3 and +3 ) if the event actually happened. The FTT was preceded by the COWAT (Lezak, 1995), which can be used to control for pre-existing differences in verbal fluency and to prime the participant to generate events in the FTT. The COWAT is a common measure of verbal fluency. It involves asking participants to say as many words as they can think of beginning with each of the three letters (F, A, S), excluding proper nouns, numbers, the same word with a different suffix, and repetitions. Participants are allowed one minute for each letter and each letter is presented in the fixed order mentioned above. The score is the sum of all acceptable words produced within the three 1-minute trials.

\section{Autobiographical Memory Test (AMT)}

The AMT has been used in numerous studies (Williams et al., 
2007) since it was developed by Williams and Broadbent (Williams \& Broadbent, 1986). In the version used in this study a total of 36 emotional words $(18 \times 2$ word sets $)$ were used to cue for memories. Each word set consists of 6 positive/pleasant, 6 negative/unpleasant and 6 neutral words. Participants were given $1 \mathrm{~min}$ in each case to retrieve a specific autobiographical memory and a specific time and place when something happened to them. Participants were told that the memory they recalled could be something that happened recently or a long time ago and that it could be an important or trivial event but that the memory should be of something that happened at a particular time on a particular day. Examples of acceptable and unacceptable responses were given. A printed version of the recall instructions was given to the participants to read. Cue words were presented on $10 \times 10 \mathrm{~cm}$ white paper and were written in black ink in capital letters $3.5 \mathrm{~cm}$ high. Words were presented in a random order for each participant. To ensure that participants understood the instructions two practice cues were given ("relieved" and "tired"). Generated memories were tape-recorded and transcribed for coding according to the criteria outlined by Williams (Williams, 2001). Specific memories were defined as events that happened in a particular instance or lasted for 1 day or less. Non-specific memories included extended memories (events that lasted for longer periods of time) and categorical memories (events that occurred repeatedly over a period of time). If the participants failed to recall a memory within the time limit or talked about things that were not memories (e.g., an opinion that is associated with the cue), their responses were classed as non-memory. We also coded semantic associations (e.g., grass is green). If the type of memory that the participants recalled was unclear, or if participants retrieved the same memory to more than one cue or offered responses that related to future events, they were prompted with the words "What is the memory that you are thinking of there?" or "Can you tell me a bit more about that memory?" In the present study analyses focus on the number of specific memories.

\section{Statistical Analyses}

Data were analyzed using the Statistical Package for Social Sciences (SPSS) version 17. All analyses used two-tailed levels of significance. Pearson correlations were used to analyze associations between variables. All variables were checked for normality and found to be suitable for parametric analyses.

\section{Results}

Mean results on the COWAT, FTT, AMT are presented in Table 1. The result showed that positive future thinking was significantly correlated with the number of specific positive autobiographical memories. Positive future thinking was also associated with negative future thinking. Furthermore, the number of specific positive autobiographical memories was correlated with both negative autobiographical memory and results on the COWAT. Finally the positive autobiographical memory was negatively correlated with extended autobiographical memory, repeated autobiographical memory, semantic association autobiographical memory and non-response autobiographical memory. As verbal fluency may account for the association between positive future thinking and the number of specific positive autobiographical memories we controlled for the COWAT in a partial correlation. The association remained statistically significant $(r=0.24, p=0.03)$. Mean results on the self-report inventories are presented in the Table. None of the self-report measures were correlated with either FTT or the AMT.

\section{Discussion}

The purpose of this study was to examine the relationship between future-oriented thinking and autobiographical memory specificity in patients with mild to moderate depression. The results indicate a small but statistically significant positive correlation between positive future thinking and positive autobiographical memory specificity.Positive future thinking was associated with both negative future thinking and positive autobiographical memory specificity, but not with negative autobiographical memory specificity. The question is why negative specific memories were not correlated with either positive or negative future-oriented thoughts. One possible explanation is that future thinking as measured by our FTT index and memory specificity as measured by the AMT reflects different processes. Indeed, while the memory specificity has been found to correlate with measures of working memory (Raes et al., 2006), the association between positive future thinking and memory specificity remained significant after controlling for verbal fluency. It may be that future thinking and memory specificity are related to the different subsystems that can partially operate independently of each other and also be influence by valence (e.g., positive versus negative events. It may be that our positive and negative experiences are relatively independent of each other (Phillips, 1968), which has also been suggested in the literature on positive and negative affect (Watson, Clark, \& Tellegen, 1988). Indeed, other researchers have also suggested that positive and negative thoughts reflect the operations of different systems rather than different change of a single system (MacLeod \& Moore, 2000).

Results on the AMT and FTT were not correlated with self-reported symptoms of depression and anxiety. However, a consistent finding in the literature is that individuals with depression report fewer specific memories on the AMT (Dalgleish et al., 2007) and fewer future events on the FTT (MacLeod, Tata, Kentish, \& Jacobsen, 1997). From a theoretical point of view it could be expected that memory specificity would be more affected in depression, whereas future thinking would be more affected in anxiety (for example generalized anxiety disorder). However, since comorbidity between depressive and anxious states is substantial (Hirschfeld, 2001), it is difficult to separate the effects of depression and anxiety in clinical samples.

There are limitations of this study including the fact that participants were recruited via advertisement for participation in a treatment trial, that the design was cross-sectional, and that we used relatively simple statistical analyses. However, the sample size was fairly large for this type of research (e.g., cognitive processes in depression), and all participants were diagnosed with major depression in a structured interview. The crosssectional character of the data can be motivated by the research question in which we have no strong theoretical reasons to assume that future thinking and memory specificity should be related in a specific temporal order in major depression. However, when it comes to outcomes it would be interesting with 
Table 1 .

Intercorrelations, Means (SDs) for the future thinking task, the autobiographical memory task, the controlled word association test, and self-report measures.

\begin{tabular}{|c|c|c|c|c|c|c|c|c|c|c|c|c|c|}
\hline Measure & 1 & 2 & 3 & 4 & 5 & 6 & 7 & 8 & 9 & 10 & 11 & 12 & Mean $(S D)$ \\
\hline 1. FTT index pos & & & & & & & & & & & & & $11.24(4.68)$ \\
\hline 2. FTT index neg & $.31 * *$ & & & & & & & & & & & & $9.00(4.41)$ \\
\hline 3. AMT pos & $.23 *$ & .07 & & & & & & & & & & & $2.91(1.59)$ \\
\hline 4. AMT neg & -.09 & .06 & $.39 * *$ & & & & & & & & & & $2.89(1.72)$ \\
\hline 5. AMT ext & .03 & -.03 & $-.27 * *$ & $-.37 * *$ & & & & & & & & & $1.63(1.46)$ \\
\hline 6. AMT repeat & .05 & .14 & $-.30 * *$ & $-.41 * *$ & .24 & & & & & & & & $1.57(1.71)$ \\
\hline 7. AMT sem ass & -.02 & -.15 & $-.37 * *$ & $-.35 * *$ & $.25 *$ & $.26^{*}$ & & & & & & & $1.99(2.12)$ \\
\hline 8. AMT non-response & -.21 & -.05 & $-.29 * *$ & -.17 & -.09 & -.21 & $-.23 *$ & & & & & & $3.81(2.67)$ \\
\hline 9. COWAT & .12 & .20 & $.26^{*}$ & .12 & -.16 & -.07 & -.15 & -.09 & & & & & $13.25(3.82)$ \\
\hline 10. BDI & -.11 & .11 & .13 & .15 & .08 & -.12 & -.17 & -.03 & -.03 & & & & $21.9(5.9)$ \\
\hline 11. MADRS & -.13 & .09 & -.06 & .05 & .05 & .05 & .01 & .02 & -.05 & $.63 * *$ & & & $21.8(3.9)$ \\
\hline 12. BAI & -.06 & .11 & .00 & .11 & .17 & -.10 & .19 & .06 & -.10 & $.45^{* *}$ & $.46 * *$ & & $15.1(7.7)$ \\
\hline 13. QOLI & .15 & .03 & -.04 & .05 & -.6 & -.07 & .03 & -.04 & -.19 & $-.37 * *$ & $-.44 * *$ & $-.24 *$ & $-.02(1.5)$ \\
\hline
\end{tabular}

$* \mathrm{p}<.05, * * \mathrm{p}<.01$. Note: FFT $=$ Future Thinking Task; AMT = Autobiographical Memory Test; COWAT = Controlled Word Association Test; BDI = Beck Depression Inventory; MADRS = Montgomery-Åsberg Depression Rating Scale; BAI = Beck Anxiety Inventory; QOLI = Quality of Life Inventory.

longitudinal design to investigate the role of future thinking and memory specificity for the long-term outcome of major depression. This has mainly been done in studies on memory specificity (Brittlebank, Scott, Williams, \& Ferrier, 1993). Another limitation is the lack of a non-depressed control group. This would have made it possible to investigate if the association between the FTT and the AMT is stronger in persons without depression. In addition, it can be argued that the measures of autobiographical memory and future thinking target different processes (specificity vs. verbal fluency combined with likelihood and valence). Hence, a study in which number of memories and their likelihood and valence had been measured would perhaps have yielded stronger associations with the FTT. Vice versa, a study of specificity of future events instead of their numbers, likelihood and valence would perhaps have been more strongly associated with memory specificity as measures by the AMT. On the other hand, in such a study shared methodology (e.g., specificity) would be a competing explanation of association. Finally, it may be that memories of the past and notions about what might occur in the future are not overlapping constructs in major depression. Indeed, in Beck's original model of depression a negative view of the future was included in the cognitive triad (Beck, Rush, Shaw, \& Emery, 1979), whereas non-specific memories of the past may be an equally important or even more distinct feature of depression.

The results presented in this paper give some support for an association between future thinking and memory specificity. Further research is needed to investigate the characteristics of depressive thinking and how it affects how the future is perceived.

\section{References}

American Psychiatric Association. (2000). Diagnostic and statistical manual of mental disorders (4th ed.). Washington, DC: American Psychiatric Press.

Beck, A. T., Epstein, N., Brown, G., \& Steer, R. (1988). An inventory for measuring clinical anxiety. Psychometric properties. Journal of Consulting and Clinical Psychology, 56, 893-897. doi: 10.1037/0022-006X.56.6.893

Beck, A. T., Rush, A. J., Shaw, B. F., \& Emery, G. (1979). Cognitive therapy of depression. New York: Guilford press.

Beck, A. T., Ward, C. H., Mendelson, M., Mock, J., \& Erbaugh, J. (1961). An inventory for measuring depression. Archives of General Psychiatry, 4, 561-571.

Brittlebank, A. D., Scott, J., Williams, J. M. G., \& Ferrier, N. (1993). Autobiographical memory in depresson: State or trait marker? British Journal of Psychiatry, 162, 118-121. doi:10.1192/bjp.162.1.118

Conway, M. A., \& Pleydell-Pearce, C. W. (2000). The construction of autobiographical memories in the self-memory system. Psychological Review, 107, 261-288. doi:10.1037/0033-295X.107.2.261

Dalgleish, T., Tchanturia, K., Serpell, L., Hems, S., Yiend, J., \& de Silva, P., et al. (2003). Self-reported abuse relates to autobiographical memory style in patients with eating disorders. Emotion, 3, 211-222. doi:10.1037/1528-3542.3.3.211

Dalgleish, T., Williams, J. M. G., Golden, A. M., Perkins, N., Barrett, L. F., \& Barnard, P. J., et al. (2007). Reduced specificity of autobiographical memory and depression: the role of executive control. Journal of Experimental Psychology, 136, 23-42.

Dickson, J. M., \& Bates, G. W. (2006). Autobiographical memories and views of the future: In relation to dysphoria. International Journal of Psychology, 41, 107-116. doi:10.1080/00207590500188025

First, M. B., Gibbon, M., Spitzer, R. L., \& Williams, J. B. W. (1997). Structured clinical interview for DSM-IV Axis I Disorders (SCID-I). Washington, DC: American Psychiatric Press.

Frisch, M. B., Cornell, J., Villanueva, M., \& Retzlaff, P. J. (1992). Clinical validation of the Quality Of Life Inventory: A measure of life satisfaction for use in treatment planning and outcome assessment. Psychological Assessment, 4, 92-101. doi:10.1037/1040-3590.4.1.92

Hirschfeld, R. M. (2001). The comorbidity of major depression and anxiety disorders: Recognition and management in primary care. Primary Care Companion to the Journal of Clinical Psychiatry, 3, 244-254.

Kremers, I. P., Spinhoven, P., \& Van der Does, A. J. W. (2004). Autobiographical memory in depressed and non-depressed patients with borderline personality disorder. British Journal of Clinical Psychology, 43, 17-29. doi:10.1080/741938208

Lezak, M. (1995). Neuropsychological assessment (3rd ed.). New York: Oxford University Press. 
MacLeod, A. K., Byrne, A., \& Valentine, J. D. (1996). Affect, emotional disorder, and future-directed thinking. Cognition and Emotion, 10, 69-86. doi:10.1080/026999396380394

MacLeod, A. K., \& Moore, R. (2000). Positive thinking revisited: Positive cognitions, well-being and mental health. Clinical Psychology and Psychotherapy, 7, 1-10.

doi:10.1002/(SICI)1099-0879(200002)7:1<1::AID-CPP228>3.0.CO; 2-S

MacLeod, A. K., Rose, G. S., \& Williams, J. M. G. (1993). Components of hopelessness about the future in parasuicide. Cognitive Therapy and Research, 17, 441-455. doi:10.1007/BF01173056

Macleod, A. K., Tata, P., Kentish, J., Carroll, F., \& Hunter, E. (1997). Anxiety, depression, and explanation-based pessimism for future positive and negative events. Clinical Psychology and Psychotherapy, 4, 15-24.

doi:10.1002/(SICI)1099-0879(199703)4:1<15::AID-CPP112>3.0.C $\underline{\mathrm{O} ; 2-\#}$

MacLeod, A. K., Tata, P., Kentish, J., \& Jacobsen, H. (1997). Retrospective and prospective cognitions in anxiety and depression. Cognition and Emotion, 11, 467-479. doi:10.1080/026999397379881

Phillips, D. L. (1968). Social class and psychological disturbance: The influence of positive and negative experience. Social Psychiatry, 3, 41-46. doi:10.1007/BF00578276

Pillemer, D. B. (2003). Directive function of autobiographical memory: The guiding power of the specific episode. Memory, 11, 193-202. doi: $10.1348 / 014466504772812940$

Raes, F., Hermans, D., Williams, J. M. G., Demyttenaere, K., Sabbe, B., \& Pieters, G., et al. (2006). Is overgeneral autobiographical memory an isolated memory phenomena in major depression? Memory, 14, 584-594. doi:10.1080/09658210600624614

Schacter, D. L., Addis, D. R., \& Buckner, R. L. (2007). Remembering the past to imagine the future: the prospective brain. Nature Reviews
Neuroscience, 8, 657-661. doi:10.1038/nrn2213

Svanborg, P., \& Åsberg, M. (2001). A comparison between the Beck Depression Inventory (BDI) and the self-rating version of the Montgomery Asberg Depression Rating Scale (MADRS). Journal of Affective Disorders, 64, 203-216. doi:10.1016/S0165-0327(00)00242-1

Vernmark, K., Lenndin, J., Bjärehed, J., Carlsson, M., Karlsson, J., \& Öberg, J., et al. (2010). Internet administered guided self-help versus individualized e-mail therapy: A randomized trial of two versions of CBT for major depression. Behaviour Research and Therapy, 48, 368-376. doi:10.1016/j.brat.2010.01.005

Watson, D., Clark, L. A., \& Tellegen, A. (1988). Development and validation of brief measures of positive and negative affect: the PANAS scales. Journal of Personality and Social Psychology, 54, 1063-1070. doi:10.1037/0022-3514.54.6.1063

Williams, J. M. G. (2001). The Autobiographical Memory Test. Bangor: University of Wales.

Williams, J. M. G. (2006). Capture and rumination, functional avoidance and executive control (CaRFAX): Three processes that underlie overgeneral memory. Cognition and Emotion, 20, 548-568. doi:10.1080/02699930500450465

Williams, J. M. G., Barnhofer, T., Crane, C., Herman, D., Raes, F., \& Watkins, E., et al. (2007). Autobiographical memory specificity and emotional disorder. Psychological Bulletin, 133, 122-148. doi:10.1037/0033-2909.133.1.122

Williams, J. M. G., \& Broadbent, K. (1986). Autobiographical memory in suicide attempters. Journal of Abnormal Psychology, 95, 144-149. doi:10.1037/0021-843X.95.2.144

Williams, J. M. G., Ellis, N. C., Tyers, C., Healy, H., Rose, G., \& Macleod, A. K. (1996). The specificity of autobiographical memory and imageability of the future. Memory \& Cognition, 24, 116-125. doi:10.3758/BF03197278 